\section{nephron \\ Clinical}

Practice
Nephron 2018;138:296-302

DOI: $10.1159 / 000485648$
Received: October 26, 2017

Accepted after revision: November 17, 2017

Published online: January 24, 2018

\title{
Ultra-Low Contrast Volume for Patients with Advanced Chronic Kidney Disease Undergoing Coronary Procedures
}

\author{
Zach Rozenbaum $^{\mathrm{a}, \mathrm{e}}$ Sydney Benchetrit ${ }^{\mathrm{b}, \mathrm{e}}$ Eliezer Rozenbaum ${ }^{\mathrm{c}, \mathrm{e}}$ \\ Eran Neumark $^{\text {d, e }}$ Morris Mosseric, e David Pereg ${ }^{c, e}$ \\ ${ }^{a}$ Department of Cardiology, Tel Aviv Sourasky Medical Center, Tel Aviv, Israel; ${ }^{b}$ Department of Nephrology and \\ Hypertension, Meir Medical Center, Kfar Saba, Israel; ' Department of Cardiology, Meir Medical Center, Kfar Saba, \\ Israel; d Biochemistry Laboratory Meir Medical Center, Kfar Saba, Israel; e Sackler Faculty of Medicine, Tel-Aviv \\ University, Tel Aviv, Israel
}

\section{Keywords}

Chronic kidney disease · Contrast-induced nephropathy .

Coronary artery disease

\begin{abstract}
Background/Aims: Contrast induced nephropathy $(\mathrm{CIN})$ is associated with adverse clinical outcomes in patients undergoing coronary interventions, particularly in patients with advanced chronic kidney. The study was aimed to assess the real-life feasibility and safety of ultra-low volume coronary procedures in patients with advanced chronic kidney disease. Methods: A prospective study that included patients with an estimated glomerular filtration rate (eGFR) $<45 \mathrm{~mL} / \mathrm{min} / 1.73 \mathrm{~m}^{2}$ ) was conducted. Coronary procedures were performed using an ultra-low contrast volume technique. Results: The 30 patients had a mean eGFR of 31.8( \pm 8$)$ $\mathrm{mL} / \mathrm{min} / 1.73 \mathrm{~m}^{2}$. Indications for coronary angiography were non-ST elevation myocardial infarction (63.3\%), unstable (20\%), and stable angina pectoris (16.7\%). Median contrast volume for diagnostic coronary angiography was $13 \mathrm{~mL}$ (in-
\end{abstract}

\section{KARGER}

(C) 2018 S. Karger AG, Basel

E-Mail karger@karger.com

www.karger.com/nef terquartile ranges [IQR] 12-14.9), and an additional $13 \mathrm{~mL}$ (IQR 8.8-14.3) for percutaneous coronary intervention (PCI). In 3 patients (10\%), a $\geq 25 \%$ increase was demonstrated in serum cystatin $\mathrm{C}$ levels $48 \mathrm{~h}$ following the procedure. None of the patients demonstrated $a \geq 25 \%$ increase in serum creatinine levels at $48 \mathrm{~h}$. Following 6 months, no patient required renal replacement therapy or unplanned coronary intervention. Conclusions: In patients with advanced chronic kidney disease, the ultra-low contrast technique is feasible and effective and can be used safely without a significant deterioration in renal function. This technique may increase the utilization of $\mathrm{PCl}$ in high-risk coronary patients with chronic kidney disease.

(c) 2018 S. Karger AG, Basel

\section{Introduction}

Contrast induced nephropathy (CIN) is associated with adverse clinical outcomes in patients undergoing coronary interventions [1-3]. Various interventions have
Dr. David Pereg

Division of Cardiology, Meir Medical Cente

59 Tchernichovsky St.

IL-44281 Kfar Saba (Israel)

E-Mail davidpe@ post.tau.ac.il 
been studied in order to reduce the risk of CIN $[4,5]$. However, no specific measures have been determined for patients with advanced chronic kidney disease. The only 2 established approaches to prevent CIN in this high-risk group are periprocedural hydration [6] and minimizing contrast volume [7]. Despite these measures, percutaneous coronary intervention (PCI) in patients with advanced renal failure is associated with up to $30 \%$ risk of CIN [3]. This leads to the underutilization of PCI in highrisk coronary patients with chronic kidney disease $[8,9]$.

PCI with ultra-low contrast volume has been described in a small study that included selected patients with chronic kidney disease [10]. Furthermore, PCI using various techniques and imaging modalities with no contrast use has recently been reported [11]. These studies were performed at a single high-volume center and included only patients with stable coronary artery disease. Moreover, several techniques and imaging modalities, which may not be widely accessible in many laboratories, were extensively employed.

The current study was aimed to assess the real-life feasibility and safety of ultra-low volume coronary procedures in patients with advanced chronic kidney disease.

\section{Material and Methods}

\section{Study Population}

We performed a prospective study that included consecutive patients with chronic kidney disease stages 3B-5 (estimated glomerular filtration rate $[\mathrm{eGFR}]<45 \mathrm{~mL} / \mathrm{min} / 1.73 \mathrm{~m}^{2}$ by the 4 -component Modification of Diet in Renal Disease [MDRM] equation [12]) for whom coronary angiography was planned to be performed. Indications for coronary angiography included non-STelevation acute coronary syndrome (ACS) with a GRACE score $>110$, and patients with stable angina pectoris and a positive noninvasive myocardial ischemia involving $>10 \%$ of left ventricle [13]. Patients were recruited at least $24 \mathrm{~h}$ prior to the procedure. Excluded were patients over 80 years of age, patients on dialysis or those planned for dialysis in the next 3 months, and patients with a history of coronary artery bypass graft. Of note, patients presenting with ST-elevation myocardial infarction or acute renal failure (defined as a creatinine elevation of $>0.3 \mathrm{mg} / \mathrm{dL}$ compared to baseline values) or patients with acute heart failure (Killip class $>1$, or those in need of treatment with intravenous diuretics during the 3 days prior to the procedure) were also excluded from the study.

\section{Renal Function Assessment}

Screening of patients amenable for the study was conducted using the simplified MDRM formula:

$$
\mathrm{eGFR}=186 \times(\mathrm{sCr}[\text { in } \mathrm{mg} / \mathrm{dL}])-1.154 \times(\text { age }[\text { in years }])-0.203
$$

For women, the product of this equation was multiplied by a factor of 0.742 .

Low Contrast Coronary Procedures for

CKD Patients
Following enrollment to the study, renal function was assessed by measuring serum cystatin $\mathrm{C}$ and creatinine. Cystatin $\mathrm{c}$ was measured using Siemens N-Latex enhanced reagent with calibration traceable to the international standard reference material. Blood samples were obtained just prior to the procedure (day 0 ), after $24 \mathrm{~h}$ (day 1 ) and following $48 \mathrm{~h}$ (day 2 ).

Endpoints

The primary endpoint was defined as a $\geq 25 \%$ raise in serum cystatin $\mathrm{C}$ or creatinine $48 \mathrm{~h}$ following the coronary procedure. Secondary endpoints included cardiovascular mortality, a need for renal replacement therapy, or unplanned coronary intervention at 6 months following the coronary procedure.

\section{Coronary Procedures}

All procedures were performed by a single experienced interventional cardiologist. All patients received prehydration with intravenous isotonic saline at a rate of $1 \mathrm{ml}$ per kilogram of body weight per hour (or $0.5 \mathrm{~mL}$ per hour in patients with severely reduced left ventricular function) starting $12 \mathrm{~h}$ prior to the procedure. The same hydration protocol was maintained for $12 \mathrm{~h}$ following the procedure. High-dose statin (mainly Atorvastatin of $40-80 \mathrm{mg}$ ) was given to patients who were not on that treatment prior to hospital admission. Angiotensin-converting-enzyme inhibitors/angiotensin II receptor blockers were not discontinued prior to the coronary procedure. The decision regarding access site, diagnostic and guide catheters, stent type, intra-procedural imaging, and pharmacotherapy was left to the discretion of the interventional cardiologist. The contrast used in all cases was Ultravist 370 (Bayer): a nonionic low osmolar contrast medium with $2 \mathrm{~h}$ half-life that may increase to $6-11 \mathrm{~h}$ in patients with renal impairment.

The ultra-low contrast technique used in the current study has been previously described [10] and has been used in patients with renal failure in our institution for several years. Key elements of this technique included use of small catheters without side-holes, a limit of contrast volume to $2 \mathrm{~mL}$ per injection, removal of contrast from the guide catheter prior to exchange of devices, an absolute avoidance of contrast "puffing" during the procedure and positioning of PCI wires and balloons with minimal contrast. When available, previous angiographic images were reviewed prior to the procedure and were displayed alongside active fluoroscopy screen as a reference.

\section{Ethical Considerations}

Preprocedural discussion with the patients included potential benefits of coronary revascularization and risks of complications, especially CIN and the possible need for renal replacement therapy. The study was approved by the institutional ethics committee and all participants provided their written informed consent. The study was registered in the NIH ClinicalTrials.gov (NCT02468401).

\section{Statistical Analysis}

Categorical variables were expressed as percentage and continuous variables were expressed as mean $\pm \mathrm{SD}$. Continuous variables were tested for normal distribution using histogram and Q-Q plot or medians with interquartile ranges (IQR). Variables were compared using the Mann-Whitney test. We conducted a linear regression with time as the independent variable and creatinine and cystatin $\mathrm{C}$ as the dependent variables. The multivariate analy-

Nephron 2018;138:296-302 
sis was conducted in the forward method for baseline characteristic according to Table 1 in addition to age and gender. The final creatinine model included mitral regurgitation, prior myocardial infarction, peripheral vascular disease, smoking, age, and gender. The final cystatin $\mathrm{C}$ model included peripheral vascular disease, age, and gender. Results were reported as b-coefficients (95\% CI). Analyses were performed with SPSS IBM Corp., Released 2013. IBM SPSS Statistics for Windows, version 22.0 (IBM Corp., Armonk, NY, USA).

\section{Results}

\section{Patient Characteristics}

Baseline characteristics of the study population are presented in Table 1. The 30 consecutive patients included in the study had a mean age of $71( \pm 7)$ years and were comprised of $46.7 \%$ females. The majority had multiple cardiac risk factors and a previous history of cardiovascular disease. All patients had advanced chronic renal failure with median creatinine of 1.85 (IQR $1.6-2$ ) $\mathrm{mg} / \mathrm{dL}$ and eGFR of $31.8( \pm 8) \mathrm{mL} / \mathrm{min} / 1.73 \mathrm{~m}^{2}$. The most common indication for coronary angiography was a non-ST elevation myocardial infarction (19 patients), followed by unstable (6 patients) and stable (5 patients) angina pectoris.

\section{Procedural Characteristics}

Procedural characteristics are presented in Tables 2 and 3. Procedures were performed via the radial approach in $80 \%$ of cases. Diagnostic coronary angiography was performed with ultra-low contrast volume of 13 $\mathrm{mL}$ (IQR 12-14.9). Nonsignificant coronary disease suitable for conservative treatment was demonstrated in 12 patients. Two patients demonstrated multi-vessel coronary disease requiring coronary artery bypass grafting and were referred for surgery. Of the remaining $16 \mathrm{pa}-$ tients who were found suitable for an ad hoc PCI, 11 underwent a single-vessel PCI, while in the remaining 5 patients, a double-vessel PCI was performed. In 2 patients who underwent PCI, staged PCI was planned at an interval of 4 weeks. Of the coronary lesions that were treated, $8(38 \%)$ were class B2 or C on the American College of Cardiology/American Heart Association classification system [14]. Only third-generation drug eluting stents were used in the study and the majority of patients received 1 or 2 stents with pre- and post-dilatation. Drug eluting balloons were used for the treatment of in-stent restenosis. Heparin was the anticoagulation agent of choice in all cases. Similar to diagnostic angiography, PCI was also performed with ultra-low contrast volume of $13 \mathrm{~mL}$ (IQR 8.8-14.3).
Table 1. Baseline characteristics of the study participants

\begin{tabular}{|c|c|}
\hline & $n=30$ \\
\hline Age, years, mean \pm SD & $71.4 \pm 6.9$ \\
\hline $\mathrm{BMI}, \mathrm{kg} / \mathrm{m}^{2}$, mean $\pm \mathrm{SD}$ & $29.5 \pm 4.8$ \\
\hline Gender, female, $\%$ & 46.7 \\
\hline Diabetes mellitus, \% & 63.3 \\
\hline Hypertension, \% & 96.7 \\
\hline Dyslipidemia, \% & 93.3 \\
\hline Current smoking, \% & 13.3 \\
\hline Prior MI, \% & 26.7 \\
\hline Prior PCI, \% & 46.7 \\
\hline PVD, $\%$ & 30 \\
\hline CVA/TIA, \% & 20 \\
\hline COPD, $\%$ & 20 \\
\hline \multicolumn{2}{|l|}{ LV systolic function, $\%$} \\
\hline Normal & 40 \\
\hline Mild LV dysfunction & 30 \\
\hline Moderate LV dysfunction & 23.3 \\
\hline Severe LV dysfunction & 6.7 \\
\hline \multicolumn{2}{|l|}{ Chronic medications, $\%$} \\
\hline Aspirin & 76.7 \\
\hline Plavix & 20 \\
\hline Statin & 80 \\
\hline ACEI/ARB & 70 \\
\hline Beta blocker & 53.3 \\
\hline Diuretics & 23.3 \\
\hline Insulin & 46.7 \\
\hline \multicolumn{2}{|l|}{ Laboratory parameters } \\
\hline Hemoglobin, mg/dL, mean \pm SD & $12.1 \pm 1.5$ \\
\hline Cholesterol, mg/dL, mean $\pm \mathrm{SD}$ & $183.6 \pm 40.1$ \\
\hline $\mathrm{LDL}, \mathrm{mg} / \mathrm{dL}$, mean $\pm \mathrm{SD}$ & $97 \pm 25.7$ \\
\hline $\mathrm{HDL}, \mathrm{mg} / \mathrm{dL}$, median (IQR) & $37(33-43)$ \\
\hline Triglycerides, mg/dL, median (IQR) & $152(134-175.5)$ \\
\hline \multicolumn{2}{|l|}{ Indication for angiography, $\%$} \\
\hline Elective & 16.7 \\
\hline Unstable angina & 20 \\
\hline STEMI & 63.3 \\
\hline
\end{tabular}

ACEI, angiotensin-converting-enzyme inhibitor; $\mathrm{ARB}$, angiotensin II receptor blockers; BMI, body mass index; COPD, chronic obstructive pulmonary disease; CVA, cerebrovascular accident; HDL, high density lipoprotein; IQR, interquartile range; LDL, low density lipoprotein; PCI, percutaneous coronary intervention; PVD, peripheral vascular disease; STEMI, ST segment elevation myocardial infarction; TIA, transient ischemic attack.

\section{Periprocedural Renal Function}

Median creatinine values (IQR) at 0,24 , and $48 \mathrm{~h}$ were 1.85 (1.6-2), 1.75 (1.53-1.9), and 1.75 (1.6-2) mg/dL respectively. Median cystatin C (IQR) at 0,24 , and $48 \mathrm{~h}$ were 1.83 (1.5-2.1), 1.85 (1.7-2.2), and $1.9(1.6-2.3) \mathrm{mg} / \mathrm{L}$ respectively. There was a significant reduction in mean serum creatinine and cystatin $\mathrm{C}$ levels at baseline and at 24 and $48 \mathrm{~h}$ (Fig. 1). In 3 patients (10\%), a $\geq 25 \%$ increase was

Rozenbaum/Benchetrit/Rozenbaum/ Neumark/Mosseri/Pereg 
demonstrated in serum cystatin Clevels $48 \mathrm{~h}$ following the coronary procedure. Of them, 2 underwent only coronary angiography without angioplasty due to nonobstructive coronary artery disease (overall contrast volume of 12 and $14 \mathrm{~mL}$ ), and 1 patient underwent a double vessel angioplasty using drug eluting stents (overall contrast volume of $26 \mathrm{~mL}$ ). Interestingly, none of the patients (including the 3 patients who developed CIN based on serum cystatin C levels) demonstrated $a \geq 25 \%$ increase in serum creatinine levels $48 \mathrm{~h}$ following coronary procedure. There were 10 patients with baseline eGFR $<30 \mathrm{~mL} / \mathrm{min} / 1.73 \mathrm{~m}^{2}$. A subanalysis of these patients with advanced renal dysfunction did not demonstrate a significant change in creatinine $(p=$ $0.179)$ or cystatin $C(p=0.614)$ in serial measurements. During the 6-month follow-up, 1 patient died due to endstage heart failure and no patient required renal replacement therapy or unplanned coronary intervention. For the 3 patients who developed CIN based on serum cystatin C levels, serum creatinine levels remained stable 5-6 months following the procedure. We further conducted a linear regression to assess renal function as a function of time that did not demonstrate a statistically significant relation for both cystatin C and creatinine. For creatinine, a 24-h increment demonstrated a $-0.05 \mathrm{mg} / \mathrm{dL}$ change (95\% CI -0.19 to $0.09, p=0.506)$ in a univariate analysis and a -0.05 $\mathrm{mg} / \mathrm{dL}$ change $(95 \% \mathrm{CI}-0.17$ to $0.07, p=0.432)$ in a multivariate analysis. For cystatin C, a 24-h increment demonstrated a change of $0.04 \mathrm{mg} / \mathrm{L}$ ( $95 \% \mathrm{CI}-0.1$ to $0.19, p=$ $0.553)$ in a univariate analysis and $0.04 \mathrm{mg} / \mathrm{L}(95 \% \mathrm{CI}$ -0.07 to $0.16, p=0.453$ ) in a multivariate analysis.

\section{Discussion}

The current study is the first to demonstrate the feasibility and safety of coronary angiography and PCI with ultralow contrast volume in consecutive real-life patients with advanced chronic kidney disease. In 3 patients (10\%), $\geq 25 \%$ increase was demonstrated in serum cystatin C levels $48 \mathrm{~h}$ following the coronary procedure. Interestingly, none of the patients (including the 3 patients who developed CIN based on serum cystatin C levels) had $\geq 25 \%$ increase in serum creatinine levels during the $48 \mathrm{~h}$ following the coronary procedure. During the follow-up after 6 months, it was found that none of the patients required renal replacement therapy or unplanned coronary intervention.

Traditionally, CIN has been assessed using serum creatinine measurements. Due to the tubular secretion of creatinine, creatinine-based equations mildly overestimate the measured glomerular filtration rate. Cystatin $\mathrm{C}$

Low Contrast Coronary Procedures for CKD Patients
Table 2. Procedural characteristics of the diagnostic coronary angiography (30 patients)

\begin{tabular}{ll}
\hline Access site, \% & \\
Radial & 80 \\
Femoral & 20 \\
Stenosis $\geq 70 \%$ & \\
LAD & 37.7 \\
Circumflex & 33 \\
RCA & 19 \\
LM & 0 \\
Contrast material, mL, median (IQR) & $13(12-14.9)$ \\
\hline
\end{tabular}

IQR, interquartile range; LAD, left anterior descending; LM, left main; RCA, right coronary artery.

Table 3. Procedural characteristics of the PCI (16 patients)

$\begin{array}{lc}\text { Target vessel, \% } & 31.3 \\ \text { LAD } & 50 \\ \text { Circumflex } & 18.7 \\ \text { RCA } & 0 \\ \text { LM } & 1.3 \pm 0.5 \\ \text { PCI vessel number, mean } \pm \text { SD } & 25 \\ \text { DEB, \% } & 75 \\ \text { DES, \% } & 1.31 \pm 1.01 \\ \text { Stent number, mean } \pm \text { SD } & 12.5 \\ \text { Staged angiography planned, \% } & \\ \text { Medications during procedure, \% } & 100 \\ \quad \text { Heparin } & 62.5 \\ \quad \text { Plavix } & 37.5 \\ \text { Ticagrelor } & 13(8.8-14.3) \\ \text { Contrast, mL, median (IQR) }\end{array}$

DEB, drug eluting balloon; DES, drug eluting stent; IQR, interquartile range; LAD, left anterior descending; LM, left main; PCI, percutaneous coronary intervention; RCA, right coronary artery.

is an alternative serum measure of kidney function that approximates direct measures of glomerular filtration rate, since it is filtered freely by the renal glomerulus and is less influenced by age, gender, or muscle mass $[15,16]$. On the other hand, different processes unrelated to kidney function such as acute inflammation may result in a significant increase in serum cystatin $\mathrm{C}$ that could erroneously be interpreted as acute kidney injury [17, 18]. Whether renal function assessment using cystatin $\mathrm{C}$ is superior to creatinine for the detection of CIN, especially in patients with advanced renal dysfunction, remains unclear. Therefore, in the current study, renal function was assessed using both serum cystatin $\mathrm{C}$ and creatinine.

Even though the volume of iodine contrast seems to be a major factor leading to CIN, there has been little

Nephron 2018;138:296-302 299 


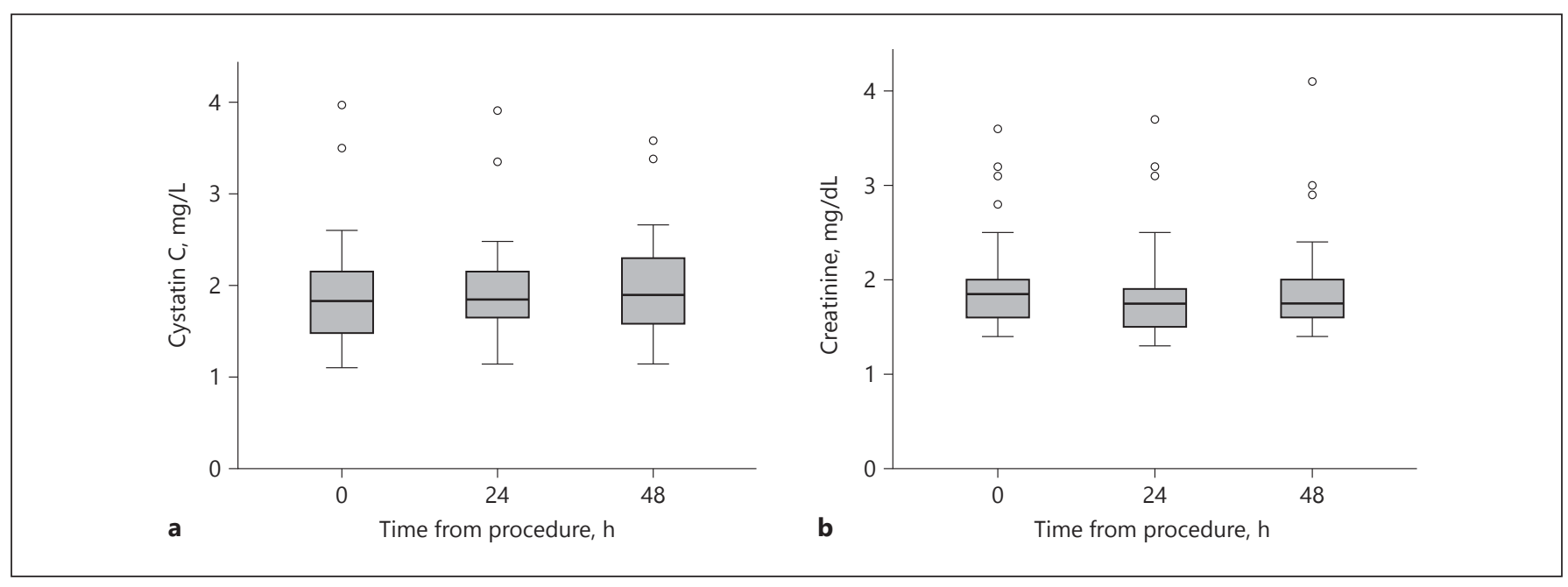

Fig. 1. Mean serum creatinine and cystatin $C$ measurements of patients according to time from procedure. a Serum cystatin $C$ ( $p$ for trend 0.048). b Serum creatinine ( $p$ for trend $<0.001)$.

investigation on the effect of contrast dose-response in patients with advanced chronic kidney disease undergoing coronary procedures with very low doses. A study on 185 patients with stages 3-5 chronic kidney disease undergoing diagnostic coronary angiography compared the risk for developing CIN according to the amount of contrast material volume [7]. The median contrast volume was $27 \mathrm{~mL}$ (IQR 20-50) and patients at the lowest quartile of contrast material administration $(14 \pm 4 \mathrm{~mL})$ were sevenfold less likely to develop CIN compared to those in the highest quartile. The ultra-low contrast material volume technique was tested in a small study that included 4 patients with advanced chronic kidney disease undergoing coronary procedures [10]. In 3 cases, coronary angiogram and PCI were performed with ultra-low contrast volume $(7.5,10$, and $14 \mathrm{~mL})$. The 4 th patient underwent a diagnostic study and multi-vessel PCI without the use of any contrast media using previous angiographic images and extensive intravascular ultrasound (IVUS) employment. None of the 4 patients demonstrated any deterioration of renal function during a 7-day follow-up period. A recent study included $31 \mathrm{pa}-$ tients with stable angina and stages 4-5 chronic kidney disease that required PCI based on a recent coronary angiogram [11]. These highly selective patients underwent zero contrast PCI using extensive IVUS images and measurement of fractional and coronary flow reserve. This technique resulted in successful PCI, no major adverse cardiovascular events, and preservation of renal function. However, these studies included highly selective patients with stable coronary artery disease and included extensive use of coronary imaging modalities, and therefore may be relevant to most cath labs worldwide. The lack of evidence regarding patients with ACS is another important limitation. The current study was designed to evaluate the feasibility and efficacy of the ultra-low contrast volume technique in 30 consecutive patients with stage $3 b-5$ chronic kidney disease referred for coronary angiography. The most common indication for coronary angiography was ACS (25 patients) followed by stable angina pectoris (5 patients), and 16 patients underwent subsequent coronary angioplasty. The study showed for the first time that the ultra-low volume technique may be applicable, effective, and safe in real-life practice.

CIN refers to a sudden deterioration in renal function within $48 \mathrm{~h}$ of intravascular administration of iodinated contrast medium. The mechanism of CIN is not completely clear and seems to be multifactorial [19]. It includes cellular damage via reactive oxygen species [20], direct cytotoxic effect on renal tubular cells [21], increased resistance to renal blood flow and renal vasoconstriction [22], and increased blood viscosity [23]. Furthermore, the contrast agent may act as an osmotic agent that can decrease water reabsorption and increase salt and water load to the distal tubules leading to reduced glomerular filtration rate [24]. On the other hand, in patients with chronic kidney disease undergoing coronary procedures, acute kidney injury may be caused by factors other than CIN. These factors may include cholesterol embolization [25], dehydration [26], medication such as ACE-inhibitors [27] and diuretics [28], heart failure, and hemodynamic instability [29].
Rozenbaum/Benchetrit/Rozenbaum/ Neumark/Mosseri/Pereg 
Of the 30 patients included in the study, $12(40 \%)$ had nonsignificant coronary artery disease that was treated conservatively. This rate is comparable to data from the PLATO study that compared treatment with Ticagrelor or Clopidogrel in patients with ACSs [30].

The current study has several limitations that warrant consideration. First, this is a single-center study that included a small number of patients; it is not possible to arrive at definitive conclusions with such a small number. However, the present study is the largest to test the ultra-low contrast volume technique and the only one that included real-life consecutive patients. Second, patients with acute ST segment elevation myocardial infarction, cardiogenic shock or heart failure, history of coronary artery bypass graft, and above the age 80 were excluded. Therefore, our results should be extrapolated to these patients with extreme caution. Finally, patients did not undergo urine collection for protein or albumin. Microalbuminuria, even though very mild, has clearly been shown to be a risk factor for both cardiovascular morbidity and mortality as well as for the progression of renal dysfunction [31].
In conclusion, in patients with advanced chronic kidney disease, the ultra-low contrast technique is feasible and effective and can be used safely without a significant deterioration in renal function. This technique may increase the utilization of PCI in high-risk coronary patients with chronic kidney disease. Since cystatin $\mathrm{C}$ was more sensitive than creatinine for the detection of CIN, future studies should prefer its use for the assessment of renal function following contrast exposure.

\section{Ethics Statement}

The study was approved by the institutional ethics committee and all participants provided their written informed consent. The study was registered in the NIHClinicalTrials.gov (NCT02468401).

\section{Disclosure Statement}

The authors declare that they have no conflicts of interest to disclose.

\section{References}

1 Marenzi G, Assanelli E, Marana I, Lauri G, Campodonico J, Grazi M, De Metrio M, Galli S, Fabbiocchi F, Montorsi P, Veglia F, Bartorelli AL: N-acetylcysteine and contrast-induced nephropathy in primary angioplasty. $\mathrm{N}$ Engl J Med 2006 ;354:2773-2782.

2 Best PJ, Lennon R, Ting HH, Bell MR, Rihal CS, Holmes DR, Berger PB: The impact of renal insufficiency on clinical outcomes in patients undergoing percutaneous coronary interventions. J Am Coll Cardiol 2002;39:11131119.

3 Rihal CS, Textor SC, Grill DE, Berger PB, Ting HH, Best PJ, Singh M, Bell MR, Barsness GW, Mathew V, Garratt KN, Holmes DR Jr: Incidence and prognostic importance of acute renal failure after percutaneous coronary intervention. Circulation 2002;105:2259-2264.

4 Maeder M, Klein M, Fehr T, Rickli H: Contrast nephropathy: review focusing on prevention. J Am Coll Cardiol 2004;44:17631771.

5 Thomsen HS: Guidelines for contrast media from the European society of urogenital radiology. AJR Am J Roentgenol 2003;181:14631471.

6 Brar SS, Aharonian V, Mansukhani P, Moore N, Shen AY, Jorgensen M, Dua A, Short L, Kane K: Haemodynamic-guided fluid administration for the prevention of contrast-induced acute kidney injury: the POSEIDON randomised controlled trial. Lancet 2014;383: 1814-1823.
7 Kane GC, Doyle BJ, Lerman A, Barsness GW, Best PJ, Rihal CS: Ultra-low contrast volumes reduce rates of contrast-induced nephropathy in patients with chronic kidney disease undergoing coronary angiography. J Am Coll Cardiol 2008;51:89-90.

8 Chertow GM, Normand SL, McNeil BJ: "Renalism": inappropriately low rates of coronary angiography in elderly individuals with renal insufficiency. J Am Soc Nephrol 2004;15: 2462-2468.

9 Charytan D, Mauri L, Agarwal A, Servoss S, Scirica B, Kuntz RE: The use of invasive cardiac procedures after acute myocardial infarction in long-term dialysis patients. Am Heart J 2006;152:558-564.

10 Nayak KR, Mehta HS, Price MJ, Russo RJ, Stinis CT, Moses JW, Mehran R, Leon MB, Kandzari DE, Teirstein PS: A novel technique for ultra-low contrast administration during angiography or intervention. Catheter Cardiovasc Interv 2010;75:1076-1083.

11 Ali ZA, Karimi Galougahi K, Nazif T, Maehara A, Hardy MA, Cohen DJ, Ratner LE, Collins MB, Moses JW, Kirtane AJ, Stone GW, Karmpaliotis D, Leon MB: Imaging- and physiology-guided percutaneous coronary intervention without contrast administration in advanced renal failure: a feasibility, safety, and outcome study. Eur Heart J 2016;37: 3090-3095.

12 Levey AS, Greene T, Kusek JW, Beck GL; MDRD Study Group: A simplified equation to predict glomerular filtration rate from serum creatinine. J Am Soc Nephrol 2000;11: 155A.

13 Authors/Task Force members, Windecker S, Kolh P, Alfonso F, Collet JP, Cremer J, Falk V, Filippatos G, Hamm C, Head SJ, Jüni P, Kappetein AP, Kastrati A, Knuuti J, Landmesser U, Laufer G, Neumann FJ, Richter DJ, Schauerte P, Sousa Uva M, Stefanini GG, Taggart DP, Torracca L, Valgimigli M, Wijns W, Witkowski A: 2014 ESC/EACTS Guidelines on myocardial revascularization: The task force on myocardial revascularization of the European society of cardiology (ESC) and the European association for cardio-thoracic surgery (EACTS) developed with the special contribution of the European association of percutaneous cardiovascular interventions (EAPCI). Eur Heart J 2014;35:2541-2619.

14 Ellis SG, Vandormael MG, Cowley MJ, DiSciascio G, Deligonul U, Topol EJ, Bulle TM: Coronary morphologic and clinical determinants of procedural outcome with angioplasty for multivessel coronary disease. Implications for patient selection. Multivessel angioplasty prognosis study group. Circulation 1990;82:1193-1202.

15 Coll E, Botey A, Alvarez L, Poch E, Quintó L, Saurina A, Vera M, Piera C, Darnell A: Serum cystatin $\mathrm{C}$ as a new marker for noninvasive estimation of glomerular filtration rate and as a marker for early renal impairment. Am J Kidney Dis 2000;36:29-34. 
16 Newman DJ, Thakkar H, Edwards RG, Wilkie M, White T, Grubb AO, Price CP: Serum cystatin $\mathrm{C}$ measured by automated immunoassay: a more sensitive marker of changes in GFR than serum creatinine. Kidney Int 1995; 47:312-318.

17 Svensson AS, Kvitting JP, Kovesdy CP, Cederholm I, Szabó Z: Changes in serum cystatin $\mathrm{C}$, creatinine, and C-reactive protein after cardiopulmonary bypass in patients with normal preoperative kidney function. Nephrology (Carlton) 2016 Jun;21:519-525.

18 Svensson AS, Kovesdy CP, Kvitting JP, Rosén M, Cederholm I, Szabó Z: Comparison of serum cystatin $\mathrm{C}$ and creatinine changes after cardiopulmonary bypass in patients with normal preoperative kidney function. Int Urol Nephrol 2013;45:1597-1603.

19 Lameire NH: Contrast-induced nephropathy - prevention and risk reduction. Nephrol Dial Transplant 2006;2111-2123.

20 Bakris GL, Lass N, Gaber AO, Jones JD, Burnett JC Jr: Radiocontrast medium-induced declines in renal function: a role for oxygen free radicals. Am J Physiol 1990;258(1 pt 2):F115-F120.

21 Heinrich MC, Kuhlmann MK, Grgic A, Heckmann M, Kramann B, Uder M: Cytotoxic effects of ionic high-osmolar, nonionic mono- meric, and nonionic iso-osmolar dimeric iodinated contrast media on renal tubular cells in vitro. Radiology 2005;235:843-849.

22 Weisberg LS, Kurnik PB, Kurnik BR: Radiocontrast-induced nephropathy in humans: role of renal vasoconstriction. Kidney Int 1992;41:1408-1415.

23 Seeliger E, Flemming B, Wronski T, Ladwig M, Arakelyan K, Godes M, Möckel M, Persson $\mathrm{PB}$ : Viscosity of contrast media perturbs renal hemodynamics. J Am Soc Nephrol 2007;18:2912-2920.

24 Bucher AM, De Cecco CN, Schoepf UJ, Meinel FG, Krazinski AW, Spearman JV, McQuiston AD, Wang R, Bucher J, Vogl TJ, Katzberg RW: Is contrast medium osmolality a causal factor for contrast-induced nephropathy? Biomed Res Int 2014;2014:931413.

25 Karalis DG, Quinn V, Victor MF, Ross JJ, Polansky M, Spratt KA, Chandrasekaran K: Risk of catheter-related emboli in patients with atherosclerotic debris in the thoracic aorta. Am Heart J 1996;131:1149-1155.

26 Swartz RD, Rubin JE, Leeming BW, Silva P: Renal failure following major angiography. Am J Med 1978;65:31-37.

27 Cirit M, Toprak O, Yesil M, Bayata S, Postaci N, Pupim L, Esi E: Angiotensin-converting enzyme inhibitors as a risk factor for contrast- induced nephropathy. Nephron Clin Pract 2006; 104:c20-c27.

28 Yuan Y, Qiu H, Hu XY, Luo T, Gao XJ, Zhao XY, Zhang J, Wu Y, Yan HB, Qiao SB, Yang YJ, Gao RL: Risk factors of contrast-induced acute kidney injury in patients undergoing emergency percutaneous coronary intervention. Chin Med J (Engl) 2017;130:45-50.

29 Mehran R, Aymong ED, Nikolsky E, Lasic Z, Iakovou I, Fahy M, Mintz GS, Lansky AJ, Moses JW, Stone GW, Leon MB, Dangas G: A simple risk score for prediction of contrastinduced nephropathy after percutaneous coronary intervention: development and initial validation. J Am Coll Cardiol 2004;44:13931399.

30 Wallentin L, Becker RC, Budaj A, Cannon CP, Emanuelsson H, Held C, Horrow J, Husted S, James S, Katus H, Mahaffey KW, Scirica BM, Skene A, Steg PG, Storey RF, Harrington RA; PLATO Investigators, Freij A, Thorsén M: Ticagrelor versus clopidogrel in patients with acute coronary syndromes. N Engl J Med 2009;361:1045-1057.

31 Keane WF, Eknoyan G: Proteinuria, albuminuria, risk, assessment, detection, elimination (PARADE): a position paper of the National Kidney Foundation. Am J Kidney Dis 1999; 33:1004-1010. 